\title{
Papain-based gel for biochemical caries removal: influence on microtensile bond strength to dentin
}

\author{
Evandro Piva(a) \\ Fabrício Aulo Ogliari(b) \\ Rafael Ratto de Moraes ${ }^{(d)}$ \\ Felipe Corá(c) \\ Sandrina Henn ${ }^{(c)}$ \\ Lourenço Correr-Sobrinho(e) \\ (a) PhD, Professor; (b)PhD Student; (c) Under- \\ graduate students - Biomaterials \\ Development and Control Center, School \\ of Dentistry, Federal University of Pelotas, \\ Pelotas, RS, Brazil. \\ (d) MSc student; (e)PhD, Professor - Department \\ of Restorative Dentistry, Piracicaba Dental \\ School, State University of Campinas, \\ Piracicaba, SP, Brazil.
}

\begin{abstract}
This study investigated the influence of a papain-based gel (Papacárie) for chemo-mechanical caries removal on bond strength to dentin. Human molars were assigned to the following groups: Group 1: sound teeth were flattened to expose dentin; Group 2: after flattening of surfaces, the papain-based gel was applied on the sound dentin; Group 3: overlying enamel from carious teeth was removed and mechanical excavation of dentin was conducted; Group 4: chemo-mechanical excavation of carious dentin was conducted using the papain-based gel. The Prime\&Bond NT or Clearfil SE Bond adhesive systems were used for restorative procedures. A microtensile bond strength test was performed, and the modes of failure were determined under SEM. The data were submitted to two-way ANOVA and Tukey's test $(\mathrm{p} \leq 0.05)$. No significant differences were observed between the sound dentin groups. For both excavation methods, Clearfil presented a significantly higher bond strength than Prime\&Bond NT. Also, for Clearfil, the mechanically excavated samples disclosed a significantly higher bond strength than the chemo-mechanically ones. For Prime\&Bond NT, no significant differences were detected between the excavation methods. Predominance of mixed failures for the sound substrate and of adhesive failures for the carious dentin one was detected. The bond strength to carious dentin of the self-etching system was negatively affected by chemo-mechanical excavation using the papain-based gel.
\end{abstract}

Descriptors: Dental caries; Tissue adhesives; Papain; Dentistry, operative; Tensile strength.

\author{
Corresponding author: \\ Evandro Piva \\ Universidade Federal de Pelotas \\ Faculdade de Odontologia \\ Departamento de Odontologia Restauradora \\ Rua Gonçalves Chaves, 457/504, Centro \\ Pelotas - RS - Brazil \\ CEP: 96015-560 \\ E-mail:piva@ufpel.edu.br
}

Received for publication on Nov 07, 2006

Accepted for publication on Apr 03, 2007 


\section{Introduction}

Excavation of carious tooth tissue plays an important role in restorative approaches. The main objectives of this process are the elimination of infected tissue, to control the progression of the lesion, and the removal of necrotic, softened dentin, to allow proper support for the filling. ${ }^{1}$ Although the advent of adhesive materials has allowed developments in minimal cavity design, the amount of carious tissue that needs to be excavated in order to successfully treat a lesion is still a challenge, as is the criteria that should be used to guide tissue removal. ${ }^{2,3}$

In 2003, a Brazilian formulation was introduced ${ }^{4}$ and commercially denominated "Papacárie" (Fórmula e Ação, São Paulo, SP, Brazil). The product is a gel based on papain, a proteolytic cisteine enzyme which presents antibacterial and anti-inflammatory properties. ${ }^{5,6}$ Papain acts as a debris-removing agent, with no harmful effect on sound tissues because of the enzyme's specificity. It acts only on affected tissues, which lack the $\alpha 1$-antitripsine plasmatic antiprotease that inhibits proteolysis in healthy tissues. ${ }^{7}$

In addition to papain, the chloramines present in the product have the potential of dissolving carious dentin by means of chlorination of the partially degraded collagen. This mechanism affects the collagen structure, dissolving hydrogen bonds and thus facilitating tissue removal..$^{8,9}$ However, because the outcome of the bonding between tooth and filling material depends on the surface properties of the remaining dentin, it is unknown whether the action mechanism of the product could interfere with the bonding to dentin. Nonetheless, there is no report in the related literature regarding the influence of this product on restoratives. Therefore, the aim of this study was to evaluate the effect of the application of a papain-based gel on the microtensile bond strength ( $\mu \mathrm{TBS}$ ) of a total-etch and of a self-etching adhesive system to sound and carious dentin. The conventional hand excavation method was used for comparison.

\section{Materials and Methods}

The research project (protocol n. 33/2005) was approved by the Ethical Research Committee, School of Dentistry, Federal University of Pelotas
(UFPel), Brazil. Forty human molar teeth were obtained. Half of them were sound teeth, whereas the remaining half was composed of molars with coronal caries extending approximately halfway through the dentin, with no indication of pulp exposure. After disinfection for a week in $0.5 \%$ chloramine $\mathrm{T}$, the teeth were stored in distilled water at $4{ }^{\circ} \mathrm{C}$ for no more than 90 days. The specimens were randomly assigned to the following groups:

- Group 1 (control): the occlusal surfaces of sound molars were removed, and the dentin was ground using 220-, 400- and 600-grit SiC papers under running water, in order to create a smooth, flat medium-depth dentin surface, with a standardized smear layer;

- Group 2: the same procedures for group 1 were performed. However, after flattening the surfaces, the papain-based gel was applied. The material remained for $60 \mathrm{~s}$ in contact with the dentin and, then, the gel was removed using a stainless steel small spoon hand excavator, up to the point that no remnants of the gel could be detected. This procedure was carried out three times, with no rinsing between each application. After the last exposure, the dentin surface was cleaned with a wet cotton pellet;

- Group 3: caries-affected teeth were used. Prior to dentin excavation, the overlying carious enamel and all surrounding walls were removed using a water-cooled, tungsten carbide bur. This protocol was carried out to minimize variables related to the cavity configuration factor during light-activation of the restorative composite. Mechanical removal of the carious dentin was conducted with a hand excavator, using the combined criteria of visual examination and dentin surface hardness;

- Group 4: decayed teeth were used, and the same preparation procedures for Group 3 were performed. However, the caries excavation procedure was conducted using the biochemical method, as described for Group 2.

Figure 1 displays the experimental design applied in this study. In order to obtain homogeneity in the substrate distribution, after mechanical or biochemical excavation, the carious teeth were sectioned in 


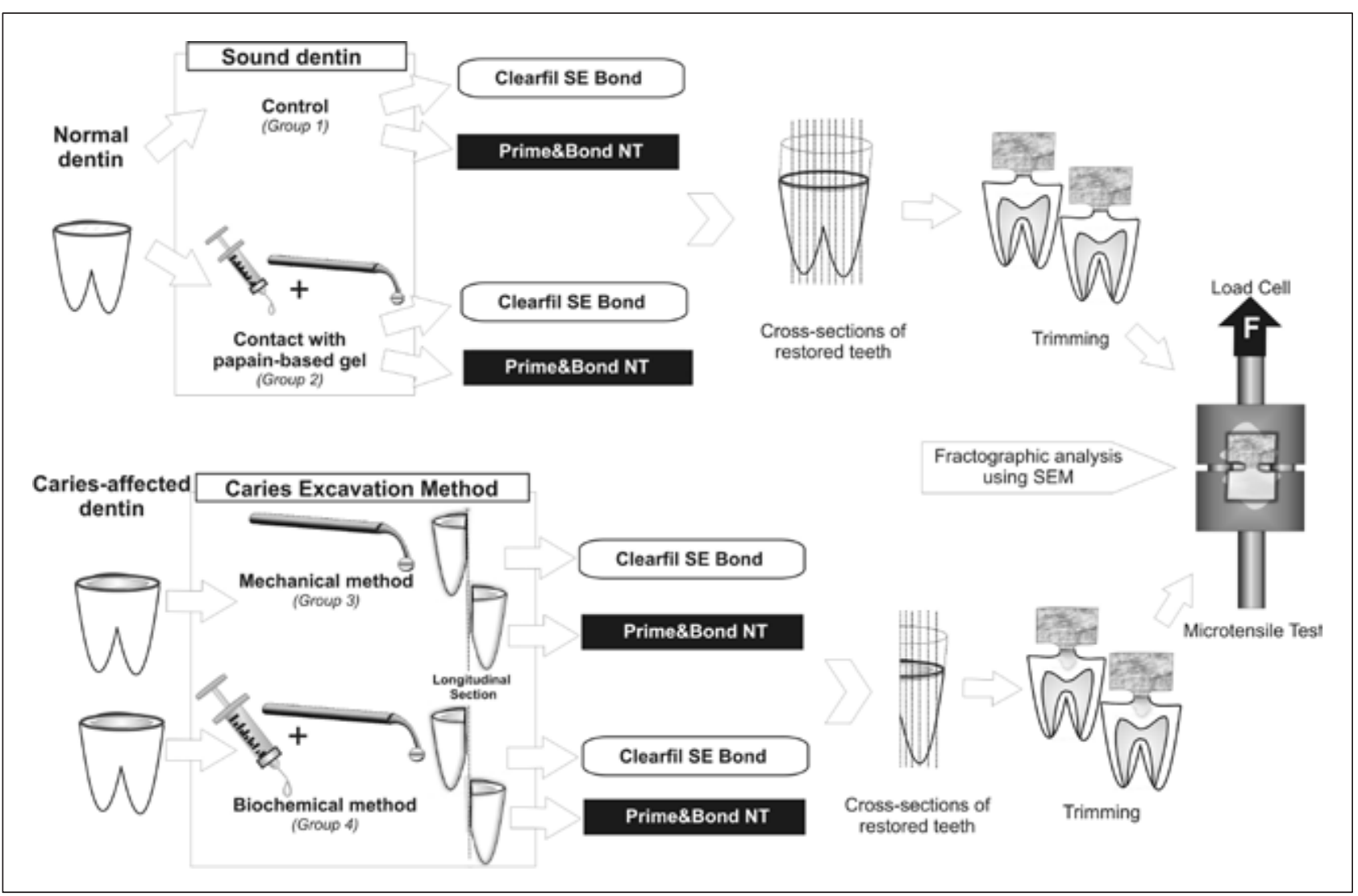

Figure 1 - Schematic representation of the experimental design used in the study.

Table 1 - Materials used in the study.

\begin{tabular}{l|l|l|l}
\hline \multicolumn{1}{c|}{ Material } & Manufacturer & \multicolumn{1}{|c}{ Composition } & Batch Code \\
\hline $\begin{array}{l}\text { Clearfil SE } \\
\text { Bond }\end{array}$ & Kuraray & $\begin{array}{l}\text { Primer: MDP, HEMA, water } \\
\text { Adhesive: MDP, HEMA, bis-GMA, hydrophobic dimethacrylates, } \\
\text { submicron silica fillers, N,N-diethanol-p-tolvidine, CQ }\end{array}$ & 00330A \\
\hline Prime\&Bond NT & Dentsply Caulk & PENTA, UDMA, nanofiller, cethylamine hydrofluoride, acetone & 0304000270 \\
\hline Charisma & Heraeus Kulzer & BisGMA, TEGDMA, silica, glass particles & 030034 \\
\hline Papacárie & $\begin{array}{l}\text { Laboratório } \\
\text { Fórmula e Ação }\end{array}$ & Papain, chloramine, toluidine blue, thickening & 0005 \\
\hline
\end{tabular}

two halves by means of a diamond saw, under running water, and each half was randomly assigned to one adhesive system: Prime\&Bond NT (Dentsply Caulk, Milford, DE, USA), a two-step, total etching system, or Clearfil SE Bond (Kuraray, Osaka, Japan), a self-etching one. The materials' compositions are presented in Table 1. For the sound molar teeth, no additional preparation was carried out.

The bonding procedures followed the manufacturers' instructions. Absorbent paper was used to leave the dentin surface with minimum visible moisture. After bonding agent application, a $4 \mathrm{~mm}-$ height crown of resin composite (Charisma, Heraeus Kulzer, Hanau, Germany) was built on the dentin surfaces, in $1.5 \mathrm{~mm}$ increments, each one of them light-activated for $40 \mathrm{~s}$ (XL3000, 3M ESPE, St. Paul, MN, USA, $450 \mathrm{~mW} / \mathrm{cm}^{2}$ ).

Following storage at $37^{\circ} \mathrm{C}$ in distilled water for $24 \mathrm{~h}$, the samples were serially sectioned longitudinally to the long axis of the tooth (Isomet 1000, Buehler, Lake Bluff, IL, USA), yielding $0.7 \mathrm{~mm}$-thick slices, which were trimmed, under copious air/water 
cooling, to form hour-glass shaped specimens. For the carious dentin, each molar half yielded an average of 3 slices, whereas an average of 5 slices per tooth was obtained for the sound substrate. Measurement of the constriction area was made using a digital caliper (Mitutoyo, Tokyo, Japan). The $\mu$ TBS test was performed in a mechanical testing machine (Model DL500, EMIC, São José dos Pinhais, PR, Brazil), at a cross-head speed of $1 \mathrm{~mm} / \mathrm{min}$ until failure. Fifteen slices were tested for each surface treatment vs. adhesive system subgroup.

Bond strength data $(\mathrm{MPa})$ from sound and from carious dentin were separately submitted to twoway ANOVA (surface treatment $\mathrm{x}$ bonding agent), followed by Tukey's test, at a significance level of $p \leq 0.05$. The differences between the sound and the caries-affected dentin were compared by the Mann Whitney test. Premature failure samples were recorded but not included in the statistical analysis. The fractured samples were examined under SEM (JSM 5600LV, Jeol Inc., Peabody, MA, USA) and the modes of failure were classified as follows: adhesive failure, cohesive failure (in dentin, adhesive or composite) or mixed failure. Failure data comparisons between carious and sound dentin, and between the adhesive systems, were performed using the MannWhitney rank sum tests.

\section{Results}

Results for the $\mu$ TBS evaluation are summarized in Table 2. The two-way ANOVA revealed that, for the caries-affected dentin, both the adhesive system $(\mathrm{p}<0.01)$ and the excavation method $(\mathrm{p}=0.01)$ were significant factors, showing a significant interaction as well $(\mathrm{p}=0.03)$. For both caries excavation methods, the Clearfil SE Bond system yielded significantly higher bond strength values in comparison to the Prime\&Bond NT one. However, for Clearfil, mechanically excavated samples disclosed significantly higher $\mu$ TBS when compared to biochemically treated ones. On the other hand, for the Prime\&Bond NT system, no significant differences were detected between specimens submitted to mechanical or biochemical excavation (Table 2).

In addition, for the sound dentin, no significant differences were detected between the specimens exposed to the papain-based gel prior to bonding procedures and the control samples. The MannWhitney test comparing sound $(32.9 \pm 11.4)$ and caries-affected dentin $(10.4 \pm 3.3)$ showed that sound dentin obtained statistically higher bond strength values $(\mathrm{p}<0.001)$.

Regarding the fractographic analysis, the modes of failure for the sound and caries-affected dentin were also significantly different $(\mathrm{p}<0.01)$. Predomi-

\begin{tabular}{|c|c|c|c|c|c|}
\hline \multirow{4}{*}{$\begin{array}{r}\text { Table } 2 \text { - Mean } \\
\text { microtensile bond } \\
\text { strength values } \pm \\
\text { standard deviation } \\
\text { and premature } \\
\text { failures (in brackets). }\end{array}$} & \multirow{2}{*}{ Adhesive } & \multicolumn{2}{|c|}{ Sound dentin* } & \multicolumn{2}{|c|}{ Caries-affected dentin** } \\
\hline & & Control & Exposure to gel & Mechanical & Biochemical \\
\hline & Clearfil SE Bond & $35.6 \pm 8.8[3]$ & $31.6 \pm 12.5[2]$ & ${ }^{\mathrm{A}} 13.9 \pm 2.4[8] \mathrm{a}$ & ${ }^{B} 10.9 \pm 2.3[7] a$ \\
\hline & Prime\&Bond NT & $31.1 \pm 14.8[4]$ & $28.8 \pm 14.0[3]$ & ${ }^{A} 8.6 \pm 1.8[9] \mathrm{b}$ & ${ }^{A} 8.3 \pm 2.9[7] \mathrm{b}$ \\
\hline
\end{tabular}

Table 3 - Percentage distribution of the specimens' modes of failure.

\begin{tabular}{c|c|c|c|c|c}
\hline \multirow{2}{*}{ Material } & \multicolumn{2}{|c|}{ Sound dentin } & \multicolumn{2}{c}{ Caries-affected dentin } \\
\cline { 3 - 6 } & \multirow{2}{*}{ Clearfil SE Bond } & Control & Exposure to gel & Mechanical & Biochemical \\
\cline { 2 - 6 } & Adhesive & $7 \%$ & $0 \%$ & $80 \%$ & $80 \%$ \\
\cline { 2 - 6 } & Cohesive & $20 \%$ & $33 \%$ & $20 \%$ & $13 \%$ \\
\hline \multirow{3}{*}{ Prime\&Bond NT } & Mixed & $73 \%$ & $67 \%$ & $0 \%$ & $7 \%$ \\
\cline { 2 - 6 } & Adhesive & $7 \%$ & $0 \%$ & $73 \%$ & $87 \%$ \\
\cline { 2 - 6 } & Cohesive & $20 \%$ & $27 \%$ & $20 \%$ & $13 \%$ \\
\hline
\end{tabular}

Significant differences were detected between the sound and the caries-affected dentin substrates $(p<0.01)$. 
nance of mixed failure was detected for the sound substrate, whereas for the carious one there was predominance of adhesive failures (Table 3).

As shown in Table 2, premature failures were observed mainly for the caries-affected dentin groups.

\section{Discussion}

According to the present outcomes, no significant differences were detected in the $\mu$ TBS evaluation between the sound dentin group exposed to the papain-based gel and the control group. Compatibility with the bonding procedure is an important requirement for any restorative technique which precedes hybridization of the substrate. In general, after mechanical excavation, the surface topography of the dentin enhances its micromechanical interlocking with the filling material. ${ }^{3}$ On the other hand, it has been shown that the dentinal surfaces formed after biochemical caries removal are very irregular with many overhangs and undercuts. ${ }^{10}$ In addition, the biochemical method removes the smear layer completely and exposes dentinal tubules. ${ }^{11}$ Nonetheless, no significant influence on bond strength to dentin has been described so far. ${ }^{12,13}$

No significant differences were detected between the adhesive systems when they were applied to the sound substrate, which was expected according to a previous investigation. ${ }^{14}$ Premature failures were observed during sectioning and trimming of the samples mainly in the carious groups, probably due to lower bond strength values. In addition, for Clearfil, the biochemically treated samples presented significantly lower bond strength values when compared to the mechanically excavated ones. Hence, it could be speculated that the papain-based gel could interfere with the micromorphology of the collagen fibrils. In general, the mechanism of biochemical removal of caries involves cleavage of polypeptide chains and/or hydrolysis of collagen cross-linkages. These cross-linkages give stability to the collagen fibrils, which become weaker and thus more prone to be removed when exposed to the gel. ${ }^{8}$ Since these fibrils will later be a part of the resin-dentin interdiffusion zone, a hybridization of poor quality could be a possible outcome. However, an influence on bond strength was observed only for the self-etching system and, therefore, an explanation for this outcome would probably rely on the characteristics of the adhesive systems.

Etching with strong acids may result in the dissolution of the sclerotic cast and/or in the complete removal of the surrounding peritubular carious dentin, and it can be decisive to an enhanced bonding to sclerotic dentin. ${ }^{15}$ According to $\mathrm{pH}$ ranking, ${ }^{16}$ the Clearfil self-etching primer can be regarded as being one of mild aggressiveness, in comparison to other self-etching systems. Although this primer presents higher $\mathrm{pH}$ than the phosphoric acid gel, the bond strength to carious dentin for the conventional twostep system was significantly lower in comparison to the self-etching one. Besides different $\mathrm{pH}$ levels, distinct commercial adhesive systems present different chemical components, like resin monomers and solvents, and it is well-recognized that the composition of the bonding resin is directly related to its mechanical properties and to its bond strength to tooth tissues. ${ }^{17,18}$

In addition, the different steps taken to apply each adhesive system could also be related to the present results. After the acid-etching and the water rinsing steps for the conventional system, complete removal of the papain-based product from the tooth surface can be expected. On the other hand, as the self-etching system lacks the rinsing step and thus the smear layer is not removed but only partially demineralized, remnants of the gel could be stagnated on the dentin surface, and could potentially interfere with the bonding mechanism. In fact, under SEM examination of gel-excavated dentin, Banerjee et al. ${ }^{2}$ (2000) described the presence of surface globules, which could be linked to remnants of the gel that had not been washed away. Also, Arvidsson et al. ${ }^{11}$ (2002) detected remnants of Carisolv on excavated dentin using infrared spectroscopy analysis. Moreover, during caries excavation using the papain-based gel, an effervescent surface activity was observed, which could be an indication of oxygen release, potentially affecting the polymerization mechanism of the bonding resin. ${ }^{19}$ On the other hand, similar findings were not observed for the sound dentin exposed to the gel. This outcome is probably related to the lower permeability of the 
healthy substrate in comparison to the caries-affected one, ${ }^{1}$ making it more difficult for the gel to be stagnated on sound surfaces.

The bond strength values for the carious dentin were significantly lower in comparison to the ones found for the sound substrate. There are several factors that influence the quality of adhesion, including the smear layer produced by the excavation process, the mineral and the organic content of the substrate and the hybrid layer formed as a result of the interaction between the bonding agents and the dentin. ${ }^{20}$ Although the intertubular carious dentin is generally hypomineralized, the dentinal tubules of the carious substrate are in general occluded with mineral deposits. ${ }^{21}$ In addition, due to the de- and re-mineralization cycles that occur during the caries process, larger calcium phosphate crystals are formed, which are less soluble than the healthy ones. ${ }^{1}$ The organic matrix of carious dentin is also different from that of the normal substrate, as a result of the denatured collagen fibrils that are still not well-recognized. All of the characteristics above can also be linked to the results of the fracture mode analysis, as the

\section{References}

1. Nakajima M, Sano H, Burrow MF, Tagami J, Yoshiyama M, Ebisu S et al. Tensile bond strength and SEM evaluation of caries-affected dentin using dentin adhesives. J Dent Res. 1995;74(10):1679-88.

2. Banerjee A, Kidd EA, Watson TF. In vitro evaluation of five alternative methods of carious dentine excavation. Caries Res. 2000;34(2):144-50.

3. Banerjee A, Kidd EA, Watson TF. Scanning electron microscopic observations of human dentine after mechanical caries excavation. J Dent. 2000;28(3):179-86.

4. Bussadori S, Castro L, Galvao A. Papain gel: a new chemomechanical caries removal agent. J Clin Pediatr Dent. 2005;30(2):115-9.

5. Monetta L. [Use of papain in curative nursing actions] [Article in Portuguese]. Rev Bras Enferm. 1987;40(1):66-73.

6. Otuka ES, Pedrazzani ES, Pioto MP. [The use of papain in plantar ulcers] [Article in Portuguese]. Rev Bras Enferm. 1996;49(2):207-14.

7. Flindt ML. Allergy to alpha-amylase and papain. Lancet. 1979;1(8131):1407-8.

8. Beeley JA, Yip HK, Stevenson AG. Chemochemical caries removal: a review of the techniques and latest developments. Br Dent J. 2000;188(8):427-30. predominance of adhesive failures for the carious dentin groups is probably related to the difficulty of the bonding resin in completely infiltrating into the exposed, altered collagen mesh.

In summary, although the papain-based gel presents a potential to be used in biochemical excavation procedures, this product needs further laboratorial and clinical investigation on its efficacy regarding caries excavation and also on its possible harmful effects on the durability of the dentin/adhesive interface.

\section{Conclusions}

According to the experimental design used in this study, for the self-etching adhesive system tested, the papain-based gel reduced the microtensile bond strength to carious dentin.

The self-etching adhesive system used in the mechanically excavated samples presented significantly higher bond strength values than in the chemo-mechanically excavated ones, whereas similar microtensile bond strength results were found for Prime\&Bond NT when used after the different excavation methods.

9. Maragakis GM, Hahn P, Hellwig E. Chemomechanical caries removal: a comprehensive review of the literature. Int Dent J. 2001;51(4):291-9.

10. Yip HK, Stevenson AG, Beeley JA. An improved reagent for chemomechanical caries removal in permanent and deciduous teeth: an in vitro study. J Dent. 1995;23(4):197-204.

11. Arvidsson A, Liedberg B, Moller K, Lyven B, Sellen A, Wennerberg A. Chemical and topographical analyses of dentine surfaces after Carisolv treatment. J Dent. 2002;30(2-3):67-75.

12. Burrow MF, Bokas J, Tanumiharja M, Tyas MJ. Microtensile bond strengths to caries-affected dentine treated with Carisolv. Aust Dent J. 2003;48(2):110-4.

13. Haak R, Wicht MJ, Noack MJ. Does chemomechanical caries removal affect dentine adhesion? Eur J Oral Sci. 2000;108(5):449-55.

14. Toledano M, Osorio R, Ceballos L, Fuentes MV, Fernandes CA, Tay FR et al. Microtensile bond strength of several adhesive systems to different dentin depths. Am J Dent. 2003;16(5):292-8.

15. Kwong SM, Cheung GS, Kei LH, Itthagarun A, Smales RJ, Tay FR et al. Micro-tensile bond strengths to sclerotic dentin using a self-etching and a total-etching technique. Dent Mater. 2002;18(5):359-69. 
- Papain-based gel for biochemical caries removal: influence on microtensile bond strength to dentin

16. Tay FR, Pashley DH. Aggressiveness of contemporary selfetching systems. I: Depth of penetration beyond dentin smear layers. Dent Mater. 2001;17(4):296-308.

17. Carrilho M, Carvalho R, Tay F, Pashley D. Effects of storage media on mechanical properties of adhesive systems. Am J Dent. 2004;17(2):104-8.

18. Ogliari FA, de Sordi MLT, Ceschi MA, Petzhold CL, Demarco FF, Piva E. 2,3-Epithiopropyl methacrylate as functionalized monomer in a dental adhesive. J Dent. 2006;34(7):472-7.
19. Cavalli V, Reis AF, Giannini M, Ambrosano GM. The effect of elapsed time following bleaching on enamel bond strength of resin composite. Oper Dent. 2001;26(6):597-602.

20. Eick JD, Gwinnett AJ, Pashley DH, Robinson SJ. Current concepts on adhesion to dentin. Crit Rev Oral Biol Med. 1997;8(3):306-35.

21. Ogawa K, Yamashita Y, Ichijo T, Fusayama T. The ultrastructure and hardness of the transparent layer of human carious dentin. J Dent Res. 1983;62(1):7-10. 